\title{
Gender differences in airways diseases
}

\author{
Olga Carvalho* \\ Institute of Histology and Embryology, Faculty of Medicin, University of Coimbra, Rua Larga, Coimbra, Portugal
}

\begin{abstract}
The worldwide clinical data show gender differences in the morbidity and mortality rates of some airway diseases, such as asthma, CF or COPD. For unknown reasons women exhibit a higher risk factor to develop and have worse clinical evolution in some inflammatory lung diseases.

Understanding the reasons underlying this gender disparity renewed the researcher's interest in this multifactorial process in which psychological, genetics and sex hormones play important key roles.

This article, review the related scientific data to better understand the mechanisms behind gender disparities in some airway diseases, which could be a useful tool for earlier diagnosis, improving therapeutics interventions and better outcome in some respiratory diseases.
\end{abstract}

\section{Introduction}

Increasing clinical epidemiologic data support gender differences in the incidence, prevalence, morbidity, and mortality of some airway diseases. Airways diseases have distinct pathophysiologies but for unknown reasons women are increasingly becoming more prevalent and experiencing high morbidity and mortality for these disorders, suggesting a higher risk factor for female gender in inflammatory lung diseases.

The gender dichotomy renewed the researcher's interest for understanding these differences in human health and disease. Probably is a multifactorial process in which psychological or social behavior, genetic inherent and/or steroids hormones play important key roles.

Steroids hormones regulate innumerous aspects in vertebrates and estrogens can influence the growth, differentiation and functioning of male and female reproductive systems organs, cardiovascular system, bone density, strength and regeneration of muscle [1] and inflammation $[2,3]$. Estrogens diffuse in and out of all cells, being retained in the specific target cells by a nuclear receptor protein, termed the estrogen receptor (ER) that controls the gene expression [4]. The ER that belongs to a superfamily of nuclear receptors [5], have two isoforms - ERa and $\operatorname{Er} \beta$ - with similar structural architecture but with distinct regions sequences [6-9].

ER $\alpha$ and ER $\beta$ are products of different genes [10], and exhibit different tissue expression $[8,9,11,12]$, divergent tissues responses and distinct physiological and pathological activities [13-16].

ERs are detected in the blastocyts stage, and during fetal life in human fetal ovary and other organs depending on the receptors isoform [17]. Studies have showed that both receptors are important for normal lung development. ERa ensures that the lungs differentiate properly, leading to normal numbers of alveoli per surface area, and ER $\beta$ modulates the development of extracellular matrix, important to the normal elastic tissue recoil pressure in lungs $[18,19]$. In the lung's mice, no ERa was detected during gestation days E15 to E19, which suggested that throughout this development period the estrogenic action is mediated predominantly by the ER $\beta$ receptor [20]. There has also been observed a gender difference in the expression of the ER $\beta$ in the fetal lung mice. Female lungs tissues expressed ER $\beta$ from developmental day E15 to E19, while the male lung tissues only express this receptor from developmental day E16 to E18. This longer exposure to estrogen action (via $E R \beta$ ), could be important to lung development [20].

In human adult life lung tissue expresses both ERs mRNA, but their transcription activity is different $[20,21]$. Several animal studies indicate that estrogens are required for the formation and complete development of the alveoli $[18,19,22]$, the maintenance of existing alveoli, the lung homeostasis [23] and the induction of alveolar regeneration in adult mice $[19,24]$.

With all the emerging data suggesting gender differences in airwyas diseases and the important role of sex hormones in inflammatory airway disesases, we will review gender dichotomy in bronchiectasis, cystic fibrosis, asthma, chronic obstructive pulmonary disease and preterm infants airwairs diseases.

\section{Airway diseases}

Bronchiectasis is a complex multifactorial chronic respiratory disease characterized by an abnormal, permanent and irreversible dilatation of the conducting bronchial airways. The main cause of bronchiectasis is the genetic disease cystic fibrosis (CF), but it may also be driven by a range of non-CF related disorders or be idiopathic [25].

In non-CF bronchiectasis the predisposed individual develop a robust inflammatory response to a pulmonary infection or tissue injury that is partially responsible for structural airways damage. The structural abnormalities allow mucus stasis, which favors continued chronic infection, and repeated cycles of infection and inflammation

*Correspondence to: Olga Carvalho, Institute of Histology and Embryology, Faculty of Medicin, University of Coimbra, Rua Larga, 3004-504 Coimbra, Portugal, E-mail: omcarvalho@gmail.com

Received: December 02, 2020; Accepted: December 24, 2020; Published: January 01, 2021 
coupled to mucus hypersecretion, leads to obstruction and collapse of smaller airways, perpetuating bronchiectasis $[26,27]$.

Gender differences are described in non-CF bronchiectasis. The prevalence is higher in males but the disease is more severe in females $[28,29]$. Poorer clinical outcomes, worse lung function and a survival disadvantage are also reported in females when compared to males across all age groups $[27,30]$. In the population under 18 years, while scarce data, the ratio of bronchiectasis suggested is $2: 1$ male: female [30].

Physical and biological mechanisms are involved in the gender dichotomy of bronchiectasis. These include comorbidities, pulmonary anatomy and physiology, chronic infection and inflammation, impaired host defenses and other environmental influences [31].

In fact, sex-related differences in respiratory tract structure, function and microbiome composition predispose females to earlier infection [25]. Females have smaller lungs and therefore smaller conducting airways [32]. Estrogens regulate the MUC5B gene expression augmenting the mucin production in the Goblet cells, which are located at the surface of pseudostratified ciliated epithelia [33].

Through functional regulation of ion transporters, estrogen and progesterone also influence airway cilia beat frequency and function thereby affecting the optimal mucociliary clearance, which when impaired, confers a higher susceptibility for microbial colonization and infection [34].

The gender differences in microbial colonization, infection and virulence can, at least in part, be attributed to differences in host immune response and bacterial pathogenicity, features influenced and regulated by sex steroid hormones [34]. The respiratory microbiome appears to have sex-specific signatures and is susceptible to a range of host immune and inflammatory consequences [35].

Cystic fibrosis (CF) is the most common life-shortening inherited disease in Caucasian population [36] and is an autosomal recessive disorder caused by mutations in the cystic fibrosis transmembrane regulator gene (CFTR), that leads to a defect in the ion transport across the epithelia of organs with exocrine function $[37,38]$.

This multi-system disease affects lungs, pancreas, gastrointestinal, reproductive system and is implicated in chronic lung infection, malabsorption, salt loss syndrome, infertility and development of other numerous morbidities. It can also impair other organs and be related with other diseases [39].

Nevertheless, the foremost cause of morbidity and mortality in CF is the lung pathophysiology [40]. In the respiratory system the CFTR protein plays a major role in determining the airway surface mucus and therefore impairs the mucociliary clearance. The airways mucus becomes abnormally thick, dehydrated, viscous and more difficult to clear by the ciliary beating, creating an environment for bacteria proliferation and infections [41-43]. These defects in the airways innate defence trigger a chain of events that includes mucus stasis and plugging, airway obstruction, infection and inflammation [38].

Several epidemiological studies have evaluated gender differences in CF patients and found that females have a lower survival rate and a worse prognosis when compared to males [34]. Nevertheless, two other studies showed no difference in the survival rate between genders but both studies included young CF patients (children and adolescents). These young patients might explain why no difference was observed, because probably the gender differences only occur after puberty [34].
It is clear that there is a CF female disadvantage in the prognosis, survival and morbidity, the called "CF gender gap" and the investigation has been focused on determining the potential crucial role of estrogen in the establishment of this gender gap $[34,44,45]$.

It has been shown that estrogen may modulate ion transport in airway epithelial cells and that this can have beneficial or deleterious effects depending on the tissue compartment and on the physiology/ pathophysiology state of the airways [46]. In the lung, estrogens appear to affects $\mathrm{Na}+$ reabsorption and fluid clearance, indicating a regulatory role for female sex hormones on the physiological conditions of respiratory system [34].

The airways surface liquid (ASL) that covers the airway epithelium and that is the main protective barrier against the entry of pathogens is thinner than the normal in CF subjects. Estrogens cause further decrease in the ASL height of bronchial cells, effect that is regulated by the estrogen receptor ER $\alpha$ [47]. Estrogens can also upregulate MUC5B gene expression in normal human airway epithelial cells, which is one of the major mucins in the human airways and the augment of mucin production results in a reduced clearance airway surface [33].

Asthma is a chronic inflammatory disease characterized by the reversible narrowing of the airways (bronchoconstriction) in response to diverse stimuli. The airway hyper-responsiveness (AHR) is defined by three salient features: 1) the airway wall inflammation that involves activation of mast cells, infiltration of eosinophils, and increased of activated T-cells; 2) mucus luminal obstruction caused by the hypersecretion of bronchial mucous glands along with infiltration of inflammatory cells; 3) vasodilatation of bronchial microvasculature with increased vascular permeability and edema [48].

There are many phenotypes and endotypes of asthma, ranging from mild with onset during childhood to severe with later onset, making asthma a broad disease with different pathologies [49]. This disease can be triggered by repeated antigen exposure (allergic asthma) or by abnormal autonomic neural regulation of airway function (nonallergic asthma) [50].

A gender discrepancy has been established and this disparity is variable throughout life [51]. Before puberty, girls have lower prevalence and severity than boys [52], but during adolescence the prevalence and morbidity in males decline concurrent with an increase in females [53]. By adulthood, women have increased prevalence compared to men [54], and women are three times more likely to be hospitalized for an asthma-related event than men [55]. This gender divergence is maintained until around the time of menopause, when a decrease in asthma prevalence is noted in women [56]. It has also been observed that asthma symptoms get worse during menstrual cycle [57] and decreased during pregnancy [58].

All these data suggest that sex hormones are important in asthma pathogenesis, but the mechanisms by which estrogen and/or androgen signaling regulate airway inflammation, mucus production, and airway hyper-reactivity are not fully elucidated [59].

Animal studies using genetic deletions of estrogens receptors and mutated androgen receptor, have showed that estrogen signaling promotes and androgen signaling attenuates inflammation $[59,60]$.

Non-immunological mechanisms, such as gender differences in airway hyper-responsiveness (AHR), smooth muscle contractility, and mucus production, may also drive the gender differences. The increased basal AHR in male mice is potentially caused by fewer numbers of 
alveoli and decreased alveolar surface area compared to female mice [18]. ERs deficient mice have showed the importance of estrogens in alveolar development [18].

Estrogen and progesterone are also important in mucus production and mucociliary clearance in the airway epithelial cells that express estrogen receptors, predominantly ER $\beta$ [59].

Asthma also seems to be more common in the overweight and obese population [61] and the interaction between body mass index (BMI) and asthma, is stronger in women than men suggesting that female sex hormones may play a role in the increased disease prevalence among obese women.

Historically considered an illness of elderly men, chronic obstructive pulmonary disease (COPD) has been correlated with the high prevalence of smoking among men. Actually, this disease is commonly observed in women, and the number of women dying per year is now greater.

Cigarette smoking remains the most important risk factor for developing COPD, however, it is becoming increasingly recognized that non-smokers may account more than one-third of all worldwide COPD cases, with women making up more than two thirds of the nonsmokers with moderate-to-severe COPD $[62,63]$.

In general, women smoke less than men, which suggest that they may be more susceptible to cigarette smoke exposure. A large population study, evidences that women appear to have more severe COPD with early-onset disease (under $60 \mathrm{yr}$ ) and a greater susceptibility with lower tobacco exposure, suggesting that women may be more vulnerable to the damaging respiratory effects of cigarette smoke $[64,65]$. Furthermore, women with severe COPD have a higher risk of hospitalization and death from respiratory failure and comorbidities [66].

The reasons for the greater susceptibility of women to developed COPD is unknown but several studies try to demonstrate the mechanisms behind these sex differences, that include factors like genetic predisposition, sex hormones and other comorbidities [67].

Smoking patterns between men and women may differ, with men taking deeper inhalations of cigarette smoke, although the number of cigarettes smoked and the age of starting smoking are similar between genders. The metabolism of cigarette smoke may differ in women due to a sex differences in the expression and activity of cytochrome P450 (CYP) enzymes. Animal experiments showed that estradiol upregulates CYP enzymes and therefore increases the cigarette smoke metabolism generate more oxidants/oxidizers, making the female lungs more susceptible oxidative stress and greater airway injury $[33,68]$.

Structurally, female's airways are relatively smaller than males for the same lung volume, so there may be a greater concentration of tobacco smoke per unit area of airway surface [69].

Only in females, the smoke-induced COPD is characterized by small airway remodelling through dysregulation of antioxidant defenses and activation of transforming growth factor- $\beta 1$ (TGF- $\beta$ ), resulting in airflow limitation. This mice study showed that these effects can be ameliorated by ovariectomy before smoke exposure and that tamoxifen (an estrogens receptor antagonist) attenuated smoke-induced oxidative stress in the lungs, suggesting that estrogens may be involved in the dysregulation of the oxidant/TGF- $\beta$ signalling axis and therefore, implicated in the disease process [70].

Compared with women, man had a higher risk of dying by respiratory causes, but the loss of the protective effect of estrogens during menopause is visible in the increased incidence of COPD in non-smoking women, that is the twice of men [71,72].

Overall, women are more prevalent and have worse prognosis in COPD but the exact mechanism behind the gender differences is still uncertain.

\section{Preterm infants and airway diseases}

Preterm infants suffer major morbidity and mortality than born term infants, showing that gestational age remains the key factor in the development of neonate diseases [73,74]. Among the morbidities, the greatest contributor to infant mortality is the respiratory distress syndrome (RDS) and subsequent bronchopulmonary dysplasia (BPD) or chronic lung disease (CLD), with higher rate in infants born prematurely due to insufficient surfactant.

Despite the advent of antenatal corticosteroid administration and postnatal surfactant use, clinical studies support a gender gap in neonatal outcomes, with a higher rate of morbidity and mortality in males [7577]. Preterm males have a higher incidence of RDS, pneumothorax, early respiratory support and subsequent bronchopulmonary displaysia (BPD) [77]. This male high mortality can be largely attributed to an increased acute respiratory disorder, which is due in part to the delayed lung maturation in male [78].

This gender disparity remains undetermined but should have a multifactorial explanation, in which structural, immunological and hormonal play an important role.

At any given gestational, male fetuses tend to weigh more and to have more alveoli and alveolar surface area than gestational age-matched females [32]. However, surfactant production appears earlier in female's lung development than in males [79]. This earlier presence of surfactant seems to prevent the early closure of alveoli and small airways, which may contribute to the higher airflow and decreased resistance of the female respiratory system [77]. In fact, earlier surfactant production is mediated by female sex hormones [22] and the lung development maturation is stimulated by estrogens [18]. The deletion of estrogen ER $\beta$ in female mice showed changes in the lung development, with an increase in alveolar size and a decrease in alveolar surface area, making these mice look like their male counterparts [77]. Furthermore, androgens have showed to inhibit surfactant production by altering epidermal growth factor and transforming growth factor $\beta 1$ [80].

Overall, the decrease in surfactant and lower gas exchange area can strongly impact the risk of developing RDS in preterm male neonates [77].

The need for postnatal respiratory support in premature neonates exposes their undeveloped lung to high concentrations of oxygen (hyperoxia), which increase oxidative stress in the lung and contribute to the development of BPD [81]. The high incidence of BPD in males is not fully understood, but one explanation could be the sexual dimorphism of surfactant synthesis, probably due to the deleterious effects of androgens in the lung developing male fetus [82].

An experimental study showed that when exposed to hyperoxia, the neonatal male mice are more susceptible, have more lung inflammation, impair alveolarization, impair pulmonary angiogenesis and higher mortality when compared with similarly female mice [83]. Gender differences in alveolarization, angiogenesis, and inflammation could explain the increased incidence of BPD in male premature neonates [83]. 


\section{Conclusion}

The worldwide increasing number of women with the airway diseases, such as asthma, CF, COPD, renewed the research interest to understand the important biological gender differences on lung mechanisms diseases.

The recognition of this gender disparity can be important for timely diagnosis, prognostic and therapeutic approaches and also for more customized patient care, incorporating increased patient education and effective counseling about symptoms particularly surrounding for example puberty, pregnancy and menopause.

The explanation for genders advantage/disadvantage in respiratory diseases remains undetermined but several factors such as anatomical, genetic, immunological and hormonal should be considered in future clinical and experimental research.

There is a special interest in understanding the search for the biological role of sex hormones in modulating airway inflammation, mucus production, cigarette de-toxification and other processes relevant to airways diseases development. In fact, the research studies show that estrogen modulates airway epithelial ion channel regulation, decrease airway surface liquid, up-regulates mucus production, change cigarette smoke de-toxification increasing susceptibility to oxidant damage by tobacco.

The more we know about the mechanisms behind gender disparities in airway diseases, the more we can improve therapeutic interventions and obtain better outcomes for both men and women.

\section{References}

1. Kitajima Y, Ono Y (2016) Estrogens maintain skeletal muscle and satellite cell functions. J Endocrinology 229: 267-275.

2. Green S, Walter P, Greene P, Krust A, Goffin C, et al. (1986) Cloning of the human oestrogen receptor cDNA. Steroid Biochem 24: 77-83

3. Morani A, Warner M, Gustafsson JA (2008) Biological functions and clinical implications of oestrogen receptors alfa and beta in epithelial tissues. J. Intern Med 264: $128-142$.

4. Jensen EV, Jacobson HI, Smith S, Jungblut PW, de Sombre ER (1972) The use of estrogen antagonists in hormone receptor studies. Gynecol Invest 3: 108-123.

5. Tenbaum S, Baniahmad A. (1997) Nuclear receptors: structure, function and involvement in disease. Int J Biochem Biol 29: 1325-1341.

6. Nilsson S, Makela S, Treuter E, Tujague M, Thomsen J, et al. (2001) Mechanisms of estrogen action. Physiol Rev 81: 1535-1565.

7. Planey SL, Kumar R, Arnott JA (2014) Estrogen receptors (ER $\alpha$ versus ER $\beta$ ): friends or foes in human biology? J Recept Signal Transduct Res 34: 1-5.

8. Carvalho O, Gonçalves C (2012a) Oestrogens receptors: structure, lung expression and role in some respiratory disease. In: Estrogens receptors. Mechanisms, structure and role in disease, George Chen (editor), Nova Science Publishers Inc., pp 133-147.

9. Carvalho $\mathrm{O}$ (2020) Estrogen receptor structure, expression and role in gender differences of airways diseases. In: Estrogens receptors. Structure, functions and clinical aspects, George Chen, Michael Tong, CA Hasselt (editors), Nova Science Publishers Inc., pp 125-148.

10. Kuiper GGJM, Carlsson B, Grandien K, Enmark E, Häggblad J, et al. (1997) Comparison of the ligand binding specificity and transcript tissue distribution of estrogen receptors alpha and beta. Endocrinology 138: 863-870.

11. Taylor AH, F. Al-Azzawi F. (2000) Immunolocalisation of oestrogen receptor beta in human tissues. J Mol Endocrinol 24: 145-155.

12. Mosselman S, Polman J, Dijkema R (1996) ER beta: identification and characterization of a novel human estrogen receptor. FEBS Letters 392: 49-53.

13. Couse JF, Lindzey J, Grandien K, Gustafsson J, Korach K (1997) Tissue distribution and quantitative analysis of estrogen receptor-alpha (ERalpha) and estrogen receptorbeta (ERbeta) messenger ribonucleic acid in the wild-type and ERalpha-knockout mouse. Endocrinology 138: 4613-4621.
14. Kawai H, Ishii A, Washiya K, Konno T, Yamaya C, et al. (2005) Estrogen receptor alpha and beta are prognostic factors in non-small cell lung cancer. $J$ Clin Cancer Res 11: 5084-5089.

15. Koehler KF, Helguero LA, Haldosén L, Warner M, Gustafsson (2005) Reflections on the discovery and significance of estrogen receptor beta. J Endocr Rev 26: 465-478.

16. Harris HA (2007) Estrogen receptor-beta: recent lessons from in vivo studies. Mol Endocrinol 21: 1-13.

17. Brandenberger AW, Tee MG, Lee JY, Chao V, Jaffe RB (1997) Tissue distribution of estrogen receptors alpha (ER-alpha) and beta (ER-beta) mRNA in the midgestational human fetus. J Clin Endocrinol Metab 82: 3509-3512.

18. Massaro D, Massaro GD (2006) Estrogen receptor regulation of pulmonary alveolar dimensions: alveolar sexual dimorphism in mice. Am J Physiol Lung Cell Mol Physiol 290 L866-870.

19. Massaro D, Massaro GD (2004) Estrogen regulates pulmonary alveolar formation, loss, and regeneration in mice. Am J Physiol Lung Cell Mol Physiol 287: L1154-1159.

20. Carvalho O, Gonçalves C (2012b) Expression of oestrogen receptors in foetal lung tissue of mice. Anat. Histol Embryol 41: 1-6.

21. Ivanova MM (2010) Sex differences in estrogen receptor subcellular location and activity in lung adenocarcinoma cells. Am J Respir Cell Mol Biol 42: 320-330.

22. Trotter A, Hilgendorff A, Kipp M, Beyer C, Kueppers E, et al. (2009) Gender-related effects of prenatal administration of estrogen and progesterone receptor antagonists on VEGF and surfactant-proteins and on alveolarisation in the developing piglet lung. Early Human Dev 85: 353-359.

23. Patrone C, Cassel TN, Pettersson K, Piao Y, Cheng G, et al. (2003) Regulation of postnatal lung development and homeostasis by estrogen receptor beta. Mol Cell Biol 23: 8542-8552.

24. Massaro D, Clerch LB, Massaro GD (2007) Estrogen receptor-alpha regulates pulmonary alveolar loss and regeneration in female mice: morphometric and gene expression studies. Am J Physiol Lung Cell Mol Physiol 293: L222-228.

25. Vidaillac C, Yong VFL, Jaggi TK, Soh M, Chotirmall SH (2018) Gender differences in bronchiectasis: a real issue? Breathe 14: 109-121.

26. Boyton RJ, Altmann DM (2016) Bronchiectasis: Current concepts in pathogenesis, immunology, and microbiology. Annu Rev Pathol 11: 523-554.

27. McShane PJ, Naureckas ET, Tino G, Strek ME (2013) Non-cystic fibrosis bronchiectasis. Am. J. Respir. Crit Care Med 188: 647-656.

28. Lonni S, Chalmers JD, Goeminne PC, McDonnell MJ, Dimakou K, et al. (2015) Etiology of non-cystic fibrosis bronchiectasis in adults and its correlation to disease severity. Ann Am Thorac Soc 12: 1764-1770.

29. Morrissey BM, Harper RW (2004) Bronchiectasis: sex and gender considerations. Clin Chest Med 25: 361-372.

30. Raghavan D, Jain R (2016) Increasing awareness of sex differences in airway diseases. Respirology 21: 449-459.

31. Pinkerton KE, Harbaugh M, Han MK, Jourdan Le Saux C, Van Winkle LS, et al (2015) Women and lung disease. Sex DIFFERENCES AND GLOBAL HEALTH DISPARITIES. Am J Respir Crit Care Med 192: 11-16.

32. Carey MA, Card JW, Voltz JW, Arbes SJ Jr, Germolec DR, et al. (2007a) It's all about sex: gender, lung development and lung disease. Trends Endocrinol Metab 18: 308-313.

33. Tam A, Morrish D, Wadsworth S, Dorscheid D, Paul Man SF, et al. (2011) The role of female hormones on lung function in chronic lung diseases. BMC Women's Health 11: 24 .

34. Saint-Criq V, Harvey BJ (2014) Estrogen and the cystic fibrosis gender gap. Steroids 81: 4-8.

35. Chamekh M, Deny M, Romano M, Lefèvre N, Corazza F, et al. (2017) Differential susceptibility to infectious respiratory diseases between males and females linked to sex-specific innate immune inflammatory response. Front Immunol 8: 1806.

36. Farrell PM (2008) The prevalence of cystic fibrosis in the European Union. $J$ Cyst Fibros 7: 450.

37. Riordan JR, Rommens JM, Kerem B, Alon N, Rozmahel R, et al. (1989) Identification of the cystic fibrosis gene: cloning and characterization of complementary DNA. Science 245: 1066-1073. 
38. Fajac I, Boeck K (2017) New horizons for cystic fibrosis treatment. Pharmacol Therapeut 70: 205-211.

39. Castellani C, Assael BM (2017) Cystic fibrosis: a clinical view. Cell Mol Life Sci 74 129-140.

40. Davis PB, Drumm M, Konstan MW (1996) Cystic fibrosis. Am J Respir Crit Care Med 154: $1229-1256$.

41. Knowles MR, Boucher RC (2002) Mucus clearance as a primary innate defense mechanism for mammalian airways. J Clin Invest 109: 571-577.

42. Matsui H, Grubb BR, Tarran R, Randell SH, Gatzy JT, et al. (1998) Evidence for periciliary liquid layer depletion, not abnormal ion composition, in the pathogenesis of cystic fibrosis airways disease. Cell 95: 1005-1015.

43. Rowe SM, Miller S, Sorscher EJ (2005) Cystic fibrosis. N Engl J Med 352: 1992-2001.

44. Sweezey NB, Ratjen F (2014) The cystic fibrosis gender gap: potential roles of estrogen. Pediatr Pulmonol 49: 309-317.

45. Zeitlin PL (2008) Cystic fibrosis and estrogens: a perfect storm. J Clin Invest 118 3841-3844.

46. Bastarache JA, Ong T, Matthay MA, Ware LB (2011) Alveolar fluid clearance is faster in women with acute lung injury compared to men. J Crit Care 26: 249-256.

47. Coakley RD, Sun H, Clunes LA, Rasmussen JE, Stackhouse JR, et al. (2008) 17betaEstradiol inhibits Ca2+-dependent homeostasis of airway surface liquid volume in human cystic fibrosis airway epithelia. J Clin Invest 118: 4025-4035.

48. Fahy JV (2015) Type 2 inflammation in asthma--present in most, absent in many. Nat Rev Immunol 15: 57-65.

49. Wu W, Bleecker E, Moore W, Busse WW, Castro M, et al. (2014) Unsupervised phenotyping of Severe Asthma Research Program participants using expanded lung data. J Allergy Clin Immunol 133: 1280-1288.

50. Bateman ED, Hurd SS, Barnes PJ, Bousquet J, Drazen JM, et al. (2008) Global strategy for asthma management and prevention: GINA executive summary. Eur Respir $J 31$ : $143-178$.

51. Zein JG, Erzurum SC (2015) Asthma is different in women. Curr Allergy Asthma Rep 15: 28

52. Kynyk JA, Mastronarde JG, McCallister JW (2011) Asthma, the sex difference. Cur Opin Pulm Med 17: 6-11.

53. Genuneit J (2014) Sex-specific development of asthma differs between farm and nonfarm children: a cohort study. Am J Respir Crit Care Med 190: 588-590.

54. Moorman JE, Zahran H, Truman BI, Molla MT (2011) Current asthma prevalence United States, 2006-2008. MMWR Suppl 60: 84-86.

55. Chen Y, Stewart P, Johansen H, McRae L, Taylor G (2003) Sex difference in hospitalization due to asthma in relation to age. J Clin Epidemiol 56: 180-187.

56. Troisi RJ, Speizer FE, Willett WC, Trichopoulos D, Rosner B (1995) Menopause, postmenopausal estrogen preparations, and the risk of adult-onset asthma. A prospective cohort study. Am J Respir Crit Care Med 152: 1183-1188.

57. Brenner BE, Holmes TM, Mazal B, Camargo CA Jr (2005) Relation between phase of the menstrual cycle and asthma presentations in the emergency department. Thorax 60: 806-809.

58. Schatz M, Harden K, Forsythe A, Chilingar L, Hoffman C, et al. (1988) The course of asthma during pregnancy, post partum, and with successive pregnancies: a prospective analysis. J Allergy Clin Immunol 81: 509-517.

59. Yung JA, Fuseini H, Newcomb DC (2018) Hormones, sex and asthma. Ann Allergy Asthma Immunol 120: 488-494.

60. Carey MA, Card JW, Bradbury JA, Moorman MP, Bakal-coates N, et al. (2007b) Spontaneous airway hyperresponsiveness in estrogen receptor-alpha-deficient mice. Am J Respir Crit Care Med 175: 126-135.

61. Beuther DA, Sutherland ER (2007) Overweight, obesity, and incident asthma: a metaanalysis of prospective epidemiologic studies. Am J Respir Crit Care Med 175: 661-666.
62. Lamprecht B, McBurnie MA, Vollmer WM, Gudmundsson G, Welte T, et al. (2011) COPD in never smokers: results from the population-based burden of obstructive lung disease study. Chest 139: 752-763.

63. Salvi SS, Barnes PJ (2009) Chronic obstructive pulmonary disease in non-smokers Lancet 374: 733-43.

64. Laviolette L, Lacasse Y, Doucet M, Lacasse M, Marquis K, et al. (2007) Chronic obstructive pulmonary disease in women. Can Respir J 14: 93-98.

65. Sørheim IC, Johannessen A, Gulsvik A, Bakke PS, Silverman EK, et al. (2010) Gender differences in COPD: are women more susceptible to smoking effects than men? Thorax 65: 480-485.

66. Prescott E, Bjerg AM, Andersen PK, Lange P, Vestbo J (1997) Gender difference in smoking effects on lung function and risk of hospitalization for COPD: results from a Danish longitudinal population study. Eur Respir J 10: 822-827.

67. Barnes PJ (2016) Sex differences in chronic obstructive pulmonary disease mechanisms Am J Respir Crit Care Med 193: 813-814.

68. Sin DD, Cohen SB, Day A, Coxson H, Pare PD (2007) Understanding the biologica differences in susceptibility to chronic obstructive pulmonary disease between men and women. Proc Am Thorac Soc 4: 671-674.

69. Merkus PJ, ten Have-Opbroek AA, Quanjer PH (1996) Human lung growth: a review. Pediatr Pulmonol 21: 383-397.

70. Tam A, Churg A, Wright JL, Zhou S, Kirby M, et al. (2016) Sex differences in airway remodeling in a mouse model of chronic obstructive pulmonary disease. Am J Respir Crit Care Med 193: 825-834.

71. Ringbaek T, Seersholm N, Viskum K (2005) Standardised mortality rates in female and males with COPD and asthma. Eur Respir J 25: 891-895.

72. Sunyer J, Antó JM, McFarlane D, Domingo A, Tobías A, et al. (1998) Sex differences in mortality of people who visited emergency rooms for asthma and chronic obstructive pulmonary disease. Am J Respir Crit Care Med 158: 851-856.

73. Kent AL, Wright IM, Abdel-Latif ME (2012) Mortality and adverse neurologic outcomes are greater in preterm male infants. Pediatrics 129: 124-131.

74. Zisk JL, Genen LH, Kirkby S, Webb D, Greenspan J, et al. (2011) Do premature female infants really do better than their male counterparts? Am J Perinatol 28: 241-246.

75. O'Driscoll DN, McGovern M, Greene CM, Molloy EJ (2018) Gender disparities in preterm neonatal outcomes. Acta Pcediatrica 107: 1494

76. Stevenson DK, Verter J, Fanaroff AA, Oh W, Ehrenkranz RA, et al. (2000) Sex differences in outcomes of very low birthweight infants: the newborn male disadvantage. Arch Dis Child Fetal Neonatal 83: F182-185.

77. Townsel CD, Emmer SF, Campbell WA, Hussain N (2017) Gender differences in respiratory morbidity and mortality of preterm neonates. Front. Pediatr 5: 1.

78. Khoury MJ, Marks JS, McCarthy BJ, Zaro SM (1985) Factors affecting the sex differential in neonatal mortality: the role of respiratory distress syndrome. Am J Obstet Gynecol 151: 777-782.

79. Fleisher B, Kulovich MV, Hallman M, Gluck L (1985) Lung profile: sex differences in normal pregnancy. Obstet Gynecol 66: 327-330.

80. Dammann CEL, Ramadurai SM, Mccants DD, Pham LD, Nielsen HC (2000) Androgen regulation of signaling pathways in late fetal mouse lung development. Endocrinology 141: 2923-2929.

81. Bhandari V (2010) Hyperoxia-derived lung damage in preterm infants. Semin Fetal Neonatal Med 15: 223-229.

82. Seaborn T, Simard M, Provost PR, Piedboeuf B, Tremblay Y (2010) Sex hormone metabolism in lung development and maturation. Trends Endocrinol Metab 21: 729738

83. Lingappan K, Jiang W, Wang L, Moorthy B (2016) Sex-specific differences in neonatal hyperoxic lung injury. Am J Physiol Lung Cell Mol Physiol 311: L481-493.

Copyright: $\mathbb{C} 2021$ Carvalho O. This is an open-access article distributed under the terms of the Creative Commons Attribution License, which permits unrestricted use, distribution, and reproduction in any medium, provided the original author and source are credited. 